\title{
HADAPI TANTANGAN GLOBAL, LEMBAGA PENDIDIKAN HINDU HARUS JADI GURUKULA MODERN
}

\author{
Oleh \\ Ni Kadek Surpi \\ Institut Hindu Dharma Negeri Denpasar \\ surpiradha@yahoo.com
}

Diterima 05 Januari 2017, direvisi 28 Juni 2017, diterbitkan 31 Agustus 2017

\begin{abstract}
Education is very important factor in building civilization. A civilization or a country will advance rapidly when its education system give such a great contributions to the development of Human Resources. The advancement of a nation is determined by the extent of the educational institution which has succeeded in building its human being into a superior human being, in order to be a dignified world citizen. Hindu civilization greatly emphasizes the importance of education. In the history of Sanatana Dharma, education gets an enormous portion along with the building of the concept of gurukula, where teachers and sisya are live together in an educational institution. Moreover, when the West has not found an established educational system, India has built the world's earliest university Thaksashila or Taxila with a highly developed teaching system. But the progress of civilization in the past has not always been well inherited in the next era. Currently, Hindus especially in Indonesia are faced with Hindu-based education that is able to answer global challenges. Not only prosecuted to build superior human resources, but educational institutions are required to mastered technology as a global phenomenon. Hindu educational institutions were requested to be capable for becoming a modern gurukula as well as capable for realizing superior human resources.
\end{abstract}

Keywords : Vidya, gurukula, education

\section{PENDAHULUAN}

Laporan terbaru dari UNESCO mengidentifikasikan ada dua masalah utama yang dihadapi oleh umat manusia pada saat menuju abad baru yaitu globalisasi dan ketahanan. Menurut laporan ini, pendidikan akan menjadi faktor kunci untuk membantu mengatasi dilema yang akan dibawa oleh dua 
masalah tersebut. Akan tetapi setiap orang akan bertanya, pendidikan jenis apa, apakah teknologi yang lebih banyak untuk membantu mengurangi tingkat buta hurup di seluruh dunia, atau gagasan tentang kebijaksanaan yang harus dijadikan variabel penting? Pertanyaan ini harus menjadi bahan kajian penting dan stategi bagi lembaga pendidikan Hindu.

Berbicara tentang sumber daya manusia, Indonesia juga belum mencapai taraf yang optimal dalam peringkat daya saing. Human Development Index 2013 yang dikeluarkan UNDP atau dikenal sebagai Indeks Pembangunan Manusia Indonesia (IPM) guna mengukur tingkat kualitas kehidupan suatu negara dari sisi pendidikan, kesehatan maupun angka harapan hidup. Data yang dipublikasikan, dari 167 negara, Indonesia berada pada rangking 121. Rangking ini mengalami peningkatan dari tahun 2012 yang berada di rangking 124. Namun jika dibandingkan dengan kelompok G-20, Indonesia berada di peringkat nomor dua paling bawah. Australia berada di peringkat 2, Amerika (3), Jerman (5), Jepang (10), Kanada (11), Inggris (26), dan Perancis (20), Rusia (55), Brasil (85), dan china (101). Sementara di kelompok Negara-negara ASEAN, peringkat daya saing sumber daya manusia Indonesia berada di bawah Singapura (9), Brunei Darussalam (30), Malaysia (62), Thailand (89) (BPS, 2014:28). Sementara menurut laporan UNDP tahun 2016, untuk tahun 2015 IPM Indonesia sebesar 0.689. Ini menempatkan Indonesia dalam kategori pembangunan manusia menengah, dan peringkat 113 dari 188 negara dan wilayah. Nilai IPM meningkat 30,5 persen dari nilai pada tahun 1990 (http://www.id.undp.org/content/ $\mathrm{d}$ a m / i n d o n e s i a / 2017 / d o c / INS2016_human_development_report.pdf). Rendahnya daya saing sumber daya manusia ini mengharuskan negara kita melakukan pembenahan pada sistem pendidikan.

Umat Hindu juga turut mengemban tanggung jawab peningkatan SDM melalui sisten pendidikan. Walau sistem pendidikan Hindu modern di India telah memiliki sejarah yang panjang, namun di Indonesia umat Hindu terus berbenah memperbaiki dan membangun sistem pendidikan yang lebih mapan sesuai dengan tantangan global. Pendidikan gurukula kuno harus ditransformasi menjadi gurukula modern yang memadukan pengetahuan spiritual dan sains sebagai prasyarat dalam menghadapi tantangan global dewasa ini.

\section{PEMBAHASAN}

\subsection{Keunggulan Pendidikan Gurukula dan Tantangan di Jaman Modern}

Dalam peradaban Veda, pengetahuan spiritual merupakan dasar dari seluruh ilmu pengetahuan, sa brahma- vidyâ sarva-vidyâ praticmhâ (muGaka upanicad 1.1.1). Para penulis Hindu menguraikan bahwa pengetahuan Hindu terdiri atas dua macam pengetahuan, yaitu pengetahuan paravidyâ (spiritual) dan aparavidyâ (sains). Karena itu pengetahuan Agama Hindu adalah yang sakral dan rasional dipadukan. Pengetahuan paravidyâ mempelajari tentang hakekat Tuhan atau sang pencipta. Berasal dari kata para = jauh, Vidyâ = pengetahuan. Jadi Para Vidyâ adalah pengetahuan yang mempelajari tentang hal yang jauh dari ukuran manusia yakni Tuhan. Aparavidyâ berasal dari kata $a=$ tidak, para $=$ jauh, Vidyâ $=$ pengetahuan. Pengetahuan aparavidyâ adalah pengetahuan yang mempelajari seluruh ciptaan (Donder, 2007:90). Jadi secara garis besar, pohon pengetahuan asvata Veda terbagi atas paravidyâ dan aparavidyâ. Pohon pengetahuan yang kokoh dengan banyak cabang dan ranting serta daun ini sepenuhnya dinaungi atau dilindungi oleh Dewi Saraswati. Dengan demikian, Veda tidak hanya berbicara pengetahuan rohani dan ritual belaka, tetapi juga pengetahuan sains yang sifatnya profan. Sehingga dalam sejarah peradaban Hindu, tidak 
pernah ada pertentangan sains dan spiritualitas, seperti yang pernah terjadi dalam peradaban Kristen yang menghukum dan membunuh para ilmuwan karena temuannya bertentangan dengan doktrin gereja. Dalam Hindu, justru melihat segala sesuatu dengan dua sisi dan kerjasama antara dua jenis pengetahuan sangat disarankan. Hindu tidak perlu membuat sidang mengadilan terhadap ilmuwan atau sains atas nama ajaran ketuhanan. Sebab ajaran Hindu dapat didekati oleh sains betatapun majunya pengetahuan. Jadi pengetahuan spiritual atau brahmavidyâ, sangat penting guna memahami pengetahuan secara utuh, holistik dan tidak mengabaikan aspek rohani.

Sistem pendidikan Hindu menekankan pada pembelajaran holistik antara pengetahuan ketuhanan (kebenaran/spiritualitas) sebagai pembangunan manusia dari dalam diri. Sebagai upaya pendidikan yang menyentuh aspek terdalam dari manusia, membangun keunggulan manusia dari dalam, sementara pengetahuan, sains dan keterampilan merupakan pendidikan dari luar diri guna membangun manusia yang unggul seutuhnya. Jadi idealnya, pendidikan berbasis Hindu harus membangun kekuatan manusia dari dalam dan dari luar diri manusia (spiritual dan sains). Upanisad menegaskan tujuan pendidikan manusia untuk membangun keinginan yang lebih baik, lebih murni, lebih halus dan lebih dalam adalah tujuan pertama pendidikan. Sehingga, tugas dari lembaga pendidikan adalah untuk mengembangkan manusia menjadi manusia yang ideal (Singh, 2005:79). Ini berarti penguatan karakter, mengendalikan keinginan dan dorongan, meningkatkan kekuatan konsentrasi dan kemauan merupakan tujuan dari pendidikan.

Perjuangan umat Hindu di Indonesia akan perbaikan Sistem Pendidikan Hindu baru saja mengalami langkah maju dengan terbitnya Peraturan Menteri Agama Republik Indonesia Nomor 56 Tahun 2014 tentang Pendidikan Keagamaan Hindu. Hal ini merupakan perjuangan dan penantian hampir 56 tahun pasca berdirinya Parisadha Hindu Dharma Indonesia tahun 1959, umat Hindu di Indonesia sangat mendambakan berdirinya pendidikan Hindu berbasis Veda. Lahirnya PMARI ini justru harus membuat seluruh Perguruan Tinggi Hindu di Indonesia untuk berbenah dan mewujudkan format pendidikan Hindu yang baik untuk sekarang dan masa depan. Umat Hindu harus belajar banyak dari keberhasilan pihak-pihak lain dalam mengelola pendidikan agama sehingga menjadi institusi pendidikan bergengsi. Di masa lalu, sistem pendidikan Hindu kuno gurukula sangat gemilang dalam peradaban Veda. Sehingga, harus dipikirkan bagaimana memajukan pendidikan Hindu di Indonesia agar mampu menjadi institusi pendidikan mapan yang disesuaikan dengan kondisi kekinian.

Pendidikan merupakan aspek yang sangat penting dalam peradaban Veda. Dinyatakan dalam Yajur Veda, 40.14 'Knowledge leads us to immortality. Dalam konsep Veda, kata pendidikan merujuk pada pengetahuan yang utuh yakni para vidya dan apara vidya. Para vidya yakni pengetahuan spiritual, pengetahuan pembebasan yang tidak menghasilkan reaksi karma, sementara apara vidya merupakan pengetahuan material yang menghasilkan reaksi karma positif. Sementara itu, jenis yang ketiga yakni avidya berupa pengetahuan material yang bertentangan dengan Veda atau kebodohan yang menghasilkan reaksi karma yang bersifat negatif atau buruk.

Dalam konteks Hindu, sistem pendidikan harus memberikan pendidikan dan pengetahuan kepada para sisya pengetahuan dan keterampilan, memiliki kemampuan untuk membedakan yang baik dan yang buruk, memiliki wawasan ke depan, bijaksana, mampu menjadi pemimpin masyarakat, penerus kebenaran, orator yang cemerlang, memajukan ilmu pengetahuan, mendidik moralitas para sisya dan mengkondisikan agar anak didik mengikuti ajaran Veda serta melindungi tradisi suci. 
Dalam sejarah umat manusia, pentingnya pendidikan dalam peradaban Veda ditunjukkan terbentuknya sistem pendidikan tradisional berupa gurukula atau ashram sejak jaman lampau dimana Acarya/guru dan sisya tinggal bersama-sama untuk mendapatkan pendidikan secara utuh. Sistem pendidikan ini sangat gemilang dimana para sisya belajar langsung dari para guru dengan tinggal bersama, melihat dan meniru pola hidup dharma dari para guru dan mempelajari secara utuh cabang-cabang dari pengetahuan Veda disertai pembelajaran filsafat, etika dan susila secara langsung. Sehingga sistem pembelajaran berlangsung sangat intensif dan membahagiakan. Selain itu, pentingnya pendidikan ditunjukkan dengan keberadaan universitas tertua di dunia yakni Thakshasila atau Taxila yang diperkirakan berdiri antara 1000 B.C hingga 500 A.D (Apte, 1949:8). Thakshasila memadukan sistem pendidikan tradisional dengan modern, ditunjang dengan perpustakaan yang memiliki koleksi buku-buku sangat mengagumkan. Baik gurukula di masa lampau dan universitas Thaksasila memiliki sistem pengajaran yang memadukan kecerdasan nalar, penguasaan pengetahuan dan keunggulan karakter. John Marshall yang telah melakukan penelitian selama 20 tahun di Thaksasila mengungkapkan Thaksasila merupakan peninggalan sejarah yang luar biasa dengan ditemukannya berbagai benda sejarah, bangunan dan sistem pendidikan yang sangat teratur setidaknya dari lima abad sebelum masehi dan lima abad setelah masehi yang mahasiswanya berasal dari tujuh bangsa berbeda yakni Persia, Macedonia, Maurya, Yunani, Seythian(Sakhas), Partian dan Kushan (Marshall, 1918:23)

Dalam konsep Veda, pengetahuan sains dan pengetahuan spiritual diajarkan secara bersama-sama guna membangun konsep pendidikan yang unggul. Tidak pernah ada pertentangan antara sains dan spiritual dalam peradaban Veda, sebagaimana pertentangan yang kita ketahui di Barat pada abad pertengahan, dimana ilmuwan yang tidak mendukung pengetahuan agama (doktrin Gereja) harus dihukum mati.

Dalam konsep pendidikan Hindu kuno tujuan utama pendidikan adalah membangkitkan keunggulan potensi sisya melalui pendidikan yang ketat selama 24 jam oleh para guru (Acarya). Para Acarya dalam sistem ini adalah para Brahmana yang memiliki keunggulan pengetahuan, kecerdasan, keluhuran budhi sehingga mampu membimbing para sisya menggali keunggulan bakat sebelum kembali ke masyarakat untuk menjadi warga negara ideal. Dalam Bhagavata Purana disebutkan bahwa Narada Muni merupakan guru ideal yang memiliki kualifikasi dharmam guhyam prinsip-prinsip kehidupan keagamaan yang paling rahasia. Kualifikasi kebrahmanaan benar-benar ditekankan dalam sistem ini sebagai sebuah kunci utama keberhasilan sistem pendidikan.

Sifat dasar atau sifat alami (svabhâva) seorang Brâhmana yakni kedamaian, pengendalian diri yang mantap, pertapaan, kesucian, memiliki toleransi, kejujuran, pengetahuan, kebijaksanaan dan taat pada prinsip keagamaan (Veda). Sifat-sifat dasar yang harus dimiliki yang merupakan ciri khas seorang brahmin ini dengan tegas dijelaskan dalam Bhagavata Purana 3.25.21.

\section{titikcava\% kâruGikâ\% suh[da\% sarva-dehiGâm ajâta-úatrava\% úantâ\% sâdhava\% sâdhu-bhûcaGâ\%}

The symptoms of sadhu are that he is tolerant, merciful and friendly to all living entities. He has no enemies, he is peaceful, he abides by the scriptures, and all his characteristics are sublime (Maharaja, $2003: 7$ )

Brahmin harus mengenal empat belas cabang dari pengetahuan Veda. Ia harus 
menguasai bahkan Gandharva-Veda atau musik dan harus menguasai ilmu pengetahuan pertanian, konstruksi rumah dan lain-lain. Pada waktu yang sama ia harus memberi instruksi ini kepada para murid dari golongan (jati) yang sesuai. Lapangan kerjanya sendiri adalah mempelajari Veda dan ia tidak boleh mempunyai sumber pendapatan lain.

\subsection{Brahmacâri Pondasi Dasar Kehidupan Manusia}

Menurut prinsip-prinsip Veda, tahap pertama dalam kehidupan hendaknya digunakan untuk kehidupan brahmacâri, demi pengembangan karakter dan kualitas spiritual. Surpi (2014:88) menyatakan menurut kitabkitab Purana, catur asrama terkait dengan usia dan karakteristik dapat digambarkan :

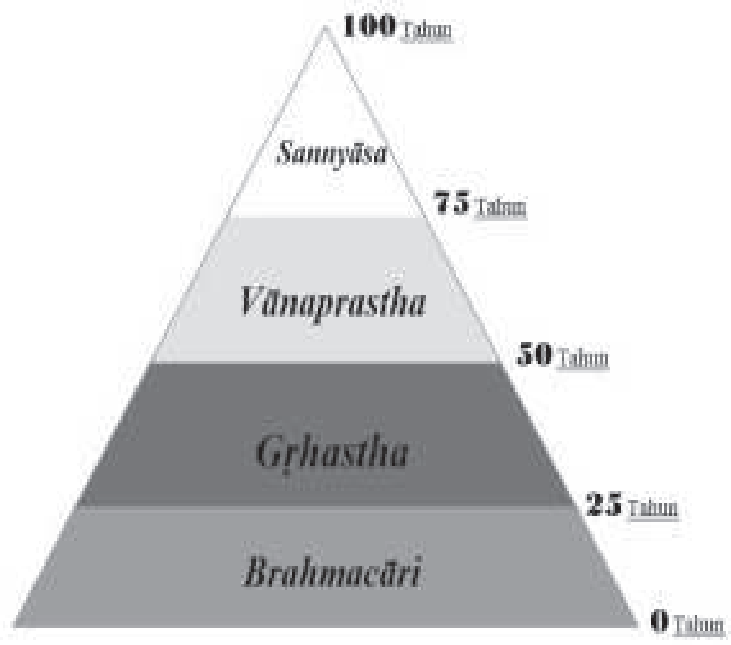

Brahmacâri merupakan tahap pertama dari kehidupan manusia. Proses belajar ini dimulai ketika manusia berumur 0 tahun atau sejak awal kelahirannya. Sementara untuk memasuki gurukula pada usia 6 tahun sampai 12 tahun. Pendidikan Veda di masa lalu, memerlukan waktu 12 tahun untuk menguasai satu cabang pengetahuan Veda. Oleh karena itu tergantung pada keinginan siswa untuk belajar program studi, masa studi bervariasi. Sehingga lama pendidikan dapat menjadi 12 tahun, 24 tahun, 36 tahun atau 48 tahun. Lulusan disebut Snataka dan upacara kelulusan
Samavartana. Olehnya, terkait dengan usia ideal memasuki jenjang g[hastha, jika seorang anak memasuki gurukula pada usia 12 tahun, ia akan belajar satu cabang atau satu tingkat yakni selama 12 tahun, sehingga usia 24 tahun akan keluar dari gurukula dan dapat melanjutkan ke jenjang berumah tangga. Sementara orang-orang tertentu yang memiliki visi yang lebih tinggi dapat memilih program selanjutnya.

Kehidupan Brahmacâri umumnya sangat keras, disiplin dan penuh pertapaan. Inilah kehidupan yang penuh dengan pengembangan yang bertujuan untuk mempersiapkan masa depan. Tahap ini khususnya bertujuan untuk berlatih; melatih diri dalam hal mengendalikan indria dan menundukkan pikiran; berlatih untuk nantinya menjadi seorang g[hastha, vânaprastha, sannyâsi. Hal ini diungkapkan dalam Srimad Bhagavatam 6.1.12 smaraGaA kîrtanaA keli\% prekcanaA guhyabhâcaGam saEkalpo dhyavasâyaú ca kriyâ-nirv[ttir eva ca

seseorang Brahmacari seharusnya tidak:

1. Berpikir tentang wanita

2. Berbicara tentang kehidupan seks

3. Bermesraan dengan wanita

4. Memandang wanita dengan penuh nafsu

5. Berbicara secara intim dengan seorang wanita

6. Memutuskan untuk melakukan hubungan seksual

7. Berusaha mengejar kehidupan seks

8. Sibuk dalam kehidupan seks

Delapan aspek brahmacâri semestinya harus menjadi pegangan bagi para mahasiswa guna mendapatkan cahaya terang pengetahuan. Kesuksesan melaksanakan dharma ini akan menjamin proses belajar yang baik.

Kitab-kitab purana menjelaskan, tahap pertama ini merupakan tahap yang sangat 
penting bagi manusia demi kebaikan hidup dan perjalanan spiritualnya. Visnu Purana menjelaskan, setelah seseorang ditasbihkan dengan benang suci maka ia harus dikirim ke pertapaan seorang guru untuk mempelajari kitab Veda. Setiap pagi dan sore ia akan melakukan pemujaan pada Surya dan Agni serta bersujud pada gurunya. Setelah doa selesai, siswa hanya akan duduk setelah gurunya. Ia tidak akan pernah menentang gurunya. Apapun nasehat gurunya akan dilakukannya. Setiap pagi murid akan bangun lebih awal dari gurunya, mengambil air dan bunga untuk gurunya. Murid akan mempelajari berbagai cabang dari Veda, berbagai pengetahuan dan pengetahuan ketuhanan. Pada akhir masa belajarnya, seorang murid wajib membayar daksina (balas jasa) pada gurunya dan meminta ijin untuk kembali ke masyarakat menempuh hidup sebagai g[hastha.

Dalam bangunan kehidupan, tahap ini merupakan tahap pembentukan landasan atau fondasi kehidupan sehingga seluruh tahap bangunan kehidupan akan menjadi kokoh dan indah, manakala tahap ini dijalani dengan sempurna. Brahmacâri sesungguhnya bukan hanya sekedar masa menuntun ilmu, melainkan sebuah masa yang sangat penting keagungan hidup. Veda menyatakan Brahmacâri harus mampu mengendalikan dirinya dari dorongan nafsu seks guna memiliki kekuatan suci cahaya kedewataan.

\section{âyus tejo balaA vîryaA prajña œrîú ca yaúas tathâ puGyatâ satpriyatvaA ca vardhate brahmacaryayâ}

"Dengan menjalani kehidupan brahmacâri, umur panjang, cahaya tubuh, kekuatan diri, vitalitas, pengetahuan, kecantikan, kemasyuran, keberuntungan dan kesetiaan serta kebenaran akan semakin meningkat " (Swami, 2012:3).
Disiplin brahmacâri jika diterapkan akan memberikan pengaruh pada vitalitas, pengetahuan dan kemampuan berkonsentrasi dalam belajar. Kitab Atharvaveda XI.5.1 juga mengungkapkan betapa pentingnya keberadaan seorang brahmacâri ;

sa dâdhâra p[thivîA divaA ca tasmin devâ\% saAmanaso bhavanti

"Seorang Brahmacari menopang bumi dan langit,"

semua Dewata berdiam di dalam diri seorang brahmacari," (Titib, 1996:393)

Kualitas seorang Brahmacari dalam tatanan Veda dibangun melalui sistem pembelajaran. Ada delapan cara belajar para sisya di jaman dulu yakni shushrusha yaitu melayani guru secara fisik, shravanam atau mendengarkan guru, bahu-shruta yakni mendengar dengan baik, grahanam menerima hal-hal yang dikatakan oleh guru, dharanam mengingat halhal yang dikatakan oleh guru, uhapoha berdiskusi dan berdebat, nijnana membuat pengetahuan khusus, belakangan istilah ini menjadi ilmu pengetahuan dan tattvabhinivesha berupa pengetahuan yang telah diperolah agar diterapkan (Machwe, 2000 : 165).

Delapan cara belajar tersebut telah membangun keunggulan peradaban Veda di jaman lampau. Saat ini, di India dan berbagai belahan dunia, sistem pendidikan yang ada sekarang dapat dilihat dalam tiga bentuk yakni (1) sistem pendidikan yang masih tetap menggunakan sistem kuno, (2) sistem pendidikan sekuler yang hanya menjejali peserta didik dengan pengetahuan sekuler dan teknologi guna mendapatkan kehidupan yang lebih baik, (3) perpaduan antara sistem pendidikan kuno dan modern, yakni sistem ini tetap mengadopsi sistem pendidikan kuno Veda tetapi dipadukan dengan kemajuan ilmu pengetahuan dan teknologi. Sistem ketiga ini 
belakangan menjadi lembaga pendidikan yang sangat terkenal, contohnya Kalinga Institute of Sosial Sciences (KISS/KIIT) yang didirikan oleh seorang filantrofis Dr. Acyuta Samanta yang telah memberikan pendidikan secara gratis terhadap 25.000 suku terasing dan warga miskin di India dengan kualitas yang sangat baik dan Amrita University di Kerala, India yang telah mendapatkan pengakuan internasional atas berbagai temuan ilmiah yang sangat bermanfaat bagi kemanusiaan.

Berpijak dari sistem pendidikan Hindu kuno dan perkembangan sistem pendidikan modern yang berbasis sciences dan teknologi, perguruan tinggi Hindu, menjadi kampus yang mencetak sumber daya manusia (SDM) Hindu unggul dengan kualifikasi ilmu agama dan Brahma Widya yang mapan, menguasai tarkasastra yang disinergikan dengan perkembangan ilmu dan teknologi serta softskill lain seperti kepemimpinan, retorika, kemampuan bekerjasama. Hal ini menjadi penting, sebab SDM Hindu tidak hanya memerlukan karakter unggul sebagai sebuah keutaamaan pendidikan Hindu tetapi mampu berbicara di panggung internasional, mampu membangun relasi dan mampu menjadi rule model. Pendidikan Hindu harus berkembang pesat, dengan pengelolaan yang profesional tetapi berdasarkan pendidikan Veda dan kearifan lokal nusantara sehingga mampu menjadi gurukula Modern yang mencetak para sarjana, para magister serta doktor yang sujana.

\subsection{Perguruan Tinggi Hindu dan Tantangan Global}

Perguruan Tinggi Hindu harus pula memikirkan kesiapan dalam menghadapi implementasi Masyarakat Ekonomi ASEAN (ASEAN Economic Community) yang sudah dilaksanakan sejak tahun 2015 lalu. Berdasarkan Global Competitiveness Report 2013-2014 yang dirilis oleh Forum Ekonomi Dunia (WEF), Daya saing Indonesia pada tahun
2013 naik ke posisi 38 dari peringkat 50 tahun 2012. Namun demikian masih rendaj jika dibandingkan dengan beberapa negara tetangga. Laporan ini mengkaji daya saing dari 148 negara di dunia, berdasarkan tingkat produktivitas dan tingkat kesejahteraan di masing-masing negara. Diperkirakan dalam beberapa tahun kedepan, harapan pekerja Indonesia yang berkualitas seperti masih sebuah mimpi. Sebab peningkatan jumlah angkatan kerja masih didominasi tingkat pendidikan yang rendah, keahlian dan sertifikasi yang masih minim. Perguruan Tinggi Hindu harus pula memikirkan untuk mencetak SDM yang berkualitas, memiliki kualifikasi dan daya saing yang tinggi sebagaimana tuntutan abad ini. Pengelolaan pendidikan tidak lagi dapat dilakukan secara tradisional dan ala kadarnya tetapi harus memperhatikan isu-isu global dan terus melakukan pembenahan ke arah yang lebih baik. perguruan tinggi Hindu jangan sampai mencetak lulusan yang tidak laku di pasaran, tidak produktif atau justru malah menambah jumlah angka pengangguran terdidik di negara ini.

Perguruan tinggi Hindu harus mampu menjadi gurukula modern di nusantara yang mampu memberikan kontribusi nyata bagi pengembangan Sumber Daya Manusia, meningkatkan Human Development Index dan kesiapan menghadapi MEA dan persaingan global. Untuk itu diperlukan sistem pembelajaran dan kurikulum yang baik, dosendosen yang berkualitas, bukan saja memiliki gelar akademik yang tinggi, tetapi pengetahuan dan keterampilan yang mapan. Kebijaksanaan Veda kuno, kebijaksanaan Timur harus dipadukan dengan perkembangan Barat agar terbangun sebuah sistem pendidikan yang mapan dan modern. Pengelolaan harus dilakukan dengan manajemen modern yang profesional. Selain itu, riset ilmiah yang berkualitas harus terus ditingkatkan, yang berguna dalam mengambil kebijakan pembangunan di negara. Dengan demikian, 
lembaga pendidikan Hindu akan menjadi lembaga yang terhormat.

\section{SIMPULAN}

Lembaga pendidikan Hindu harus diperjuangkan bersama-sama dan bersinergi dengan banyak pihak, sebab jika tidak akan tertinggal jauh dan terlindas arus modernitas. perguruan tinggi Hindu harus pula menjadi agen perubahan dengan mampu menghasilkan Sumber Daya Manusia (SDM) yang tangguh untuk hidup di tengah arus global, bukan menghasilkan lulusan yang justru tidak mampu bersaing dan tidak mengerti dengan cepatnya arus perkembangan dunia. Perguruan tinggi harus meningkatkan sumber daya, pengelolaan sistem pendidikan yang unggul demi menjawab tantangan global. Orang Hindu harus menjadi SDM unggul bukan saja mendapatkan ijazah dan bergelar sarjana. Kedepan, umat Hindu Indonesia harus lebih banyak menghasilkan tenaga-tenaga profesional yang mampu berkarya di kancah nasional dan internasional, para politisi, intrepreneur, dan bidang-bidang penting lainnya. Orang Hindu Bali unggul secara genetik tetapi keunggulan itu akan menjadi sempurna manakala dibarengi dengan pendidikan, profesionalisme, keberanian dan karakter yang baik. Ini menjadi tugas berat dari perguruan tinggi ditengah masih rendahnya daya beli masyarakat dan kemauan untuk menempuh pendidikan tinggi. Perguruan Tinggi Hindu juga harus mampu menarik anak-anak muda untuk menempuh pendidikan tinggi semakin banyak setiap tahun.

\section{DAFTAR PUSTAKA}

Apte, D.G., 1949. Universities in Ancient India. Baroda: Fakulty of Education and Psychology Maharaja Sayajirai University of Baroda.

Baktisvarupa Damodara Svami, 2004. Vedanta dan Sains. P.T. Cintya: Denpasar.
Bose, A.C., 2000. Panggilan Veda (The Call Of The Vedas). Penterjemah I Wayan Maswinara. Surabaya: Paramita.

BPS. 2014. Indeks Pembangunan Manusia 2014 Metode Baru. Jakarta : Badan Pusat Statistik. Katalog BPS 4102002

Donder, I Ketut, 2007. Kosmologi Hindu Penciptaan, Pemeliharaan dan Peleburan serta Penciptaan Kembali Alam Semesta. Surabaya : Paramita

Klostermaier, Klaus K. 1990. A Survey of Hinduism. New Delhi, India: Munshiram Manoharlal.

Machwe, Prabhakar. 2000. Konstribusi Hindu terhadap Ilmu Pengetahuan dan Peradaban. Denpasar: Widya Dharma.

Maharaja, Sripada Bhaktisvarupa Damodara, 2003. Bhagavata Sevarpanam A Glipse of the Relationship between a Discipline and the spiritual Master in the Tradition of Bhagavata Culture. Kolkata : University of Bhagavata Culture Press.

Marshall, John., 1918. A Guide to Taxila. Calcutta : Superintendent Government Printing India.

Prabhupada, Sri Srimad A.C. Bhaktivedanta Svami, 1972. Bhagavad-gita Menurut Aslinya. ISKCON: Hanoman Sakti Di Bawah Lisensi The Book trust International,Inc

Prabhupada, Sri Srimad A.C. Bhaktivedanta Svami, 1982. Ajaran Abadi Upadesamrta.P.T Pustaka: Jakarta

Prabhupada, Sri Srimad A.C. Bhaktivedanta Svami, 1982. Raja Vidya Raja Pengetahuan. P.T. Vika Press

Saraswati, Sri Chandrasekharendra, 2009. Peta Jalan Veda. Judul Asli The Vedas. Penerjemah Hira Ghindwani dan Ni Putu Anggia Jenny. Jakarta : Media Hindu 
Surpi, Ni Kadek., 2014. Konsep dan Implementasi Varnasrama Dharma menurut Kitab-Kitab Purana. Hasil Penelitian. IHDN Denpasar.

Singh, Ranvir., 2005. Veda Abad 21 Vol. I. Surabaya: Paramita.

Swami, Bhakti Vikasa. 2012. Brahmacari dalam Kesadaran Krsna. Denpasar : Yayasan Bhaktivedanta Indonesia.
Tim Penyusun, 2005. Pedoman Penyelenggaraan Pasraman. Surabaya: Paramita.

Titib, I Made, 2004. Purana Sumber Ajaran Komprehensif. Surabaya : Paramita.

Titib, I Made. 2006. Veda, Sabda Suci Pedoman Praktis Kehidupan. Surabaya: Penerbit Paramita. 